\title{
MOLECULAR SURVEILLANCE OF HEPATITIS AND TUBERCULOSIS INFECTIONS IN A COHORT EXPOSED TO METHYL ISOCYANATE
}

\section{PRADYUMNA K. MISHRA ${ }^{1,2}$, ARPIT BHARGAVA ${ }^{1,2}$, NEELAM PATHAK ${ }^{1}$, PRABHA DESIKAN ${ }^{3}$, KEWAL K. MAUDAR ${ }^{4}$, SUBODH VARSHNEY ${ }^{4}$, RAHUL SHRIVASTAVA ${ }^{1,5}$, and ARUNA JAIN ${ }^{6}$}

\author{
${ }^{1}$ Bhopal Memorial Hospital \& Research Centre, Bhopal, India \\ Research Wing \\ ${ }^{2}$ Tata Memorial Centre, ACTREC, Navi, Mumbai, India \\ Division of Translational Research \\ ${ }^{3}$ Bhopal Memorial Hospital \& Research Centre, Bhopal, India \\ Department of Microbiology \\ ${ }^{4}$ Bhopal Memorial Hospital \& Research Centre, Bhopal, India \\ Department of Surgical \& Medical Gastroenterology \\ ${ }^{5}$ Maulana Azad National Institute of Technology, Bhopal, India \\ Department of Bioinformatics \\ ${ }^{6}$ Bhopal Memorial Hospital \& Research Centre, Bhopal, India \\ Department of Pathology
}

\begin{abstract}
Objective: The potential toxic effects on the immune system exerted by occupational and accidental environmental exposures and underlying molecular regulatory mechanisms involved in the etiology and progression of infectious diseases are now being characterized. The Bhopal gas tragedy is undoubtedly one of the worst industrial disasters in the history of mankind. After 25 years of accidental exposure to methyl isocyanate (MIC), severe systemic ailments still continue to preoccupy the lives of the affected population that survived this tragedy. We have performed a molecular surveillance study to characterize hepatitis and tuberculosis infections amongst the first and the second generation of survivors exposed to MIC. Materials and Methods: Both outdoor and indoor patients referred for molecular diagnosis of hepatitis B virus (HBV), hepatitis C virus (HCV) and Mycobacterium tuberculosis (MTB) were examined. Qualitative analysis for $\mathrm{HBsAg}$, anti-HBc, anti-HCV through ELISA was performed, while BacT/ALERT and Ziehl-Neelson technique were utilized for the assessment of tuberculosis. Detection and quantification of viral and bacterial nucleic acid and characterization of hepatitis genotypes were analyzed using real-time and end-point PCR techniques. Results: The results suggest that $\mathrm{HBV}$ infections are most common among the MIC-exposed cohort, followed by extra-pulmonary and pulmonary MTB and $\mathrm{HCV}$ infections. Genotype 3 is the most prevalent $\mathrm{HCV}$ genotype among the survivors. Failure to detect $\mathrm{HBsAg}$, anti-HBc and anti-HCV through ELISA, and tuberculosis by culture and Ziehl-Neelson stain, indicates higher prevalence of occult hepatitis and latent tuberculosis in the affected population. Conclusions: Our study underscores the importance of hospital-based records used as a data source for monitoring possible environmental health hazards. As the risk of progress of infection is often influenced by conditions and periods of environmental chemical exposure, therefore, insights of interconnected molecular pathways will further illuminate the gene-environment association and might offer valuable information for rational drug design.
\end{abstract}

Key words:

Bhopal gas tragedy, Molecular epidemiology, Occult hepatitis, Latent tuberculosis, Translational research

Received: August 19, 2010. Accepted: December 6, 2010.

Address reprint request to P.K. Mishra, Scientific Officer - E, Division of Translational Research, Tata Memorial Centre, ACTREC, Navi Mumbai — 410210 , India (e-mail:pkm_8bh@yahoo.co.uk). 


\section{INTRODUCTION}

Environmental alterations that are imperceptible, but perilous, resulting from human activities pose a new threat and a global challenge. Demographic factors such as population growth, increased urbanization, and alteration of habitats of disease-carrying insects and animals have been related to the spread and outbreak of infectious and malignant diseases [1]. Patterns of antimicrobial resistance and disease surveillance studied in recent decades have been comprehensively attributed to the global rise in the levels of air, water and soil pollution [2]. Pesticides, air pollutants, industrial waste and heavy metals, through a broad array of genetic and epigenetic mechanisms, have significantly altered the immune cell functions, thereby imposing a greater threat to human lives than infections [3-5]. The Bhopal gas tragedy represents the worst industrial disaster in the history of modern world. After 25 years of organic exposure to accidental leakage of methyl isocyanate (MIC), severe illnesses including ocular, respiratory, reproductive, immunological, genetic and psychological ailments still continue to haunt the lives of the population that survived this tragedy [6]. The cause and genesis of the accident, spectrum of health effects, constituents of the toxic gas cloud and their possible role in the causation of adverse effects are well-debated [7]. Thanks to cellular model systems, the molecular mechanisms underlying the toxico-genomic implications of MIC exposure have now been better understood [8-12]. However, it has been increasingly realized that the study of the human aspect of the tragedy had perhaps been neglected. A modest number of published findings is limited to histopathological reports especially concerning lungs and small cross-sectional studies delineating symptomatology and clinical morbidity in the survivors $[13,14]$. Recently, indepth molecular investigations have provided ample evidence of immunological alterations in the MIC-exposed cohorts $[15,16]$. These findings call for institutionalizing coherent efforts to comprehend the long-term morbidity studies in the affected population.

In the past, hospital-based records were seldom utilized as a data source for monitoring possible occupational health effects [17]. In the current study, we have performed a retrospective analysis of molecular diagnostics records for the surveillance of hepatitis and Mycobacterium tuberculosis (MTB) infections amongst the first and the second generation of survivors of the Bhopal gas tragedy. Data from January 2006 to March 2010 on the tests conducted at Research Wing, Bhopal Memorial Hospital and Research Centre, Bhopal India, a super specialty medical institute embarked upon the responsibility of providing free health care to the affected population has been analyzed.

\section{MATERIALS AND METHODS}

\section{Subject Selection}

During the period from January 2006 to March 2010 samples from the outdoor and indoor patients visiting different clinical departments of Bhopal Memorial Hospital \& Research Centre, Bhopal, India were referred to Research Wing for molecular diagnosis of hepatitis B virus (HBV), hepatitis C virus (HCV) and MTB. EDTA blood was collected for the detection of $\mathrm{HBV}$ and $\mathrm{HCV}$, while different body fluids including plural fluid, bronchial alveolar lavage, CSF and pus were collected for diagnosis of pulmonary and extra-pulmonary MTB. In addition, formalin fixed and paraffin embedded tissue specimens were also collected for screening extra-pulmonary MTB. As the study was institutionalized after two decades of the organic exposure, a very careful and deliberate attempt was made to characterize the subjects to ensure that they were indeed exposed to MIC. The exposure of the subjects to MIC was ascertained on the basis of the following criteria: a) Physical presence and address of stay on the night of the MIC leak from the factory; b) Distance from the factory; c) Protective measures taken, at the time of the gas 
leak, if any; d) Remained outdoor or indoor; e) If outdoor, what was the activity profile i.e., running, or exertion, or walking, or driving, etc.; f) Overall symptomatic profiles (like respiratory, cutaneous and ocular ones, etc.) on the night of the accident to corroborate organic exposure. The protocol for sample collection as per Institutional Review Board guidelines of the Bhopal Memorial Hospital and Research Centre was strictly followed.

\section{Reagents}

Qualitative screening for $\mathrm{HBsAg}$, anti-HBc and anti-HCV was done by using ELISA kits from Diasorin S.p.A., Saluggia, Vercelli, Italy. For nucleic acid isolation of DNeasy Blood \& Tissue kit, QIAamp virus spin kit and QIAamp viral RNA mini extraction kits (Qiagen, Hilden, Germany) were used. Quantitative estimation of viral and bacterial nucleic acid was performed through Light $\mathrm{Cy}$ cler 2.0 (Roche Diagnostics, Mannheim, Germany) by using LC PCR MTB detection kit, Real Art HBV LC PCR kit (Artus GmbH, Hamburg, Germany) and HCV Real Time RT-PCR kit (Shanghai ZJ Bio-Tech, Shanghai, China).

\section{Qualitative assessment}

Qualitative assessment of HBV and HCV was performed by following the kit protocol for the detection of HBsAg, anti-HBc and anti-HCV, while BacT/ALERT 3D system (bioMérieux Inc., North Carolina, USA) and classic ZiehlNeelson technique were utilized for the qualitative assessment of MTB [18-20].

\section{Quantification of MTB DNA through LC PCR}

Bacterial DNA was isolated from the fluid and tissue specimens by using DNeasy Blood \& Tissue kit and following all necessary instructions from the manufacturer. Realtime assay was performed in thus extracted DNA with the help of fluorescence resonance energy transfer probes using standard kit protocol. Absolute quantification of bacterial load was performed with the use of Light Cycler software 4.0 with appropriate quantitative standards (MTB positive controls), and by following the guidelines for the quantitative analysis on the Light Cycler 2.0 instrument $[18,19]$.

\section{Quantification of the viral nucleic acid}

Extraction of viral nucleic acid (HBV DNA and HCV RNA) was done using QIAamp virus spin kit and QIAamp viral RNA mini extraction kit (Qiagen, Hilden, Germany) as per the manufacturer's instructions. Briefly, DNA/RNA was isolated by lysis of viral particles under highly denaturing conditions followed by binding of viral DNA/RNA to a silicagel-based membrane (QIAamp membrane) in the QIAamp Mini spin column and washing with buffer AW1 and AW2. DNA/RNA was then eluted using DNase/RNase-free elution buffer and was detected using RealArt HBV LC PCR kit and HCV Real Time RT-PCR kit through Light Cycler 2.0 (Roche Diagnostics, Mannheim, Germany) following all the necessary instructions from the supplier $[20,21]$.

\section{HCV genotyping}

Following the quantification, identification of HCV genotypes was done using Linear Array HCV genotyping kit (Roche Diagnostics, Mannheim, Germany) as per the supplier's protocol. Briefly, HCV RNA was amplified through COBAS AMPLICOR (Roche Diagnostics, Mannheim, Germany) using biotinylated primers and the amplicon was subjected to hybridization with the genotype specific probes attached on genotyping strips. After hybridization, the attached amplicon was washed and an enzyme (Horse radish peroxidase) was added followed by the addition of a substrate (3,3'-tetramethylbenzidine $\left.+\mathrm{H}_{2} \mathrm{O}_{2}\right)$ to develop a band which is specific to a particular genotype. The developed bands were analyzed in order to identify a genotype using a reference strip [22]. 


\section{RESULTS}

A total of 36 wards with the population of approximately 559835 subjects were marked as being "gas-affected", by the State Department of Bhopal Gas Tragedy Relief and Rehabilitation. This exposed population has been reported to suffer from chronic ailments such as pulmonary fibrosis, bronchial asthma, chronic obstructive pulmonary disease, emphysema, recurrent chest infections, keratopathy and corneal opacities (ICMR Report). Bhopal Memorial Hospital \& Research Centre, a super-specialty medical institute, is embarked upon the responsibility of providing tertiary health care services to the surviving population of the tragedy. The hospital has issued "smart cards" having unique identification numbers to all individuals affected due to the organic exposure. The smart cards and cross-examination of the patient's details from the medical records section of the hospital was verified for each individual included in the present work. We assured that the individuals included were from affected zones of Bhopal Gas Tragedy (within $2.5 \mathrm{~km}$ from the plant). Since 26 years have elapsed, the individuals born after 3 December 1984 (presently below 26 years) were excluded from the study.

The present study aimed at molecular epidemiological surveillance of Mycobacterium tuberculosis and hepatitis infections in the cohort exposed to MIC. The results of our study suggested that HBV infections are most common among the MIC-exposed cohort. A sample of the total of 644 subjects was referred for the screening for HBV out of which 417 (64.75\%) subjects were found to be positive through real time PCR. The overall positivity of males was also observed to be higher than that of females and the maximum number of positive cases was observed in the males aged 28-40 years. In addition, false negative qualitative diagnosis (HBsAg-ELISA) of 33 cases (12 samples from the age group 28-40 years; 15 samples from the age group 40-60 years and 06 subjects from the age group 60-80 years) was also observed. Approximately all of these 33 subjects (except 2) were reported positive for the presence of anti-Hbc antibody, while real time PCR screening confirmed the presence of HBV DNA in all of these samples. No false negative or positive case in real time PCR screening was observed, which was confirmed by the specified negative, positive and internal controls (Table 1).

In case of $\mathrm{HCV}$, a total of 284 subjects were screened for the probable HCV infections, out of which 89 subjects were reported positive for HCV RNA. Unlike that of HBV, the maximum number of cases were from males from the age group 40-60 years. This group also reported 3 false negative cases through routine qualitative

Table 1. Screening patterns of HBV among the MIC-exposed cohort*

\begin{tabular}{|c|c|c|c|c|c|c|c|}
\hline \multirow{3}{*}{$\begin{array}{c}\text { Age } \\
\text { (years) }\end{array}$} & \multirow{3}{*}{ Sex } & \multicolumn{4}{|c|}{ ELISA } & \multirow{2}{*}{\multicolumn{2}{|c|}{ Real Time PCR }} \\
\hline & & \multicolumn{2}{|c|}{ HBsAg } & \multicolumn{2}{|c|}{ anti-HBc } & & \\
\hline & & positive & negative & positive & negative & positive & negative \\
\hline \multirow[t]{2}{*}{$28-40$} & male & 136 & 80 & 146 & 70 & 148 & 68 \\
\hline & female & 39 & 25 & 39 & 25 & 39 & 25 \\
\hline \multirow[t]{2}{*}{$40-60$} & male & 121 & 82 & 137 & 66 & 137 & 66 \\
\hline & female & 38 & 45 & 40 & 43 & 40 & 43 \\
\hline \multirow[t]{2}{*}{$60-80$} & male & 42 & 18 & 48 & 12 & 48 & 12 \\
\hline & female & 4 & 14 & 5 & 13 & 5 & 13 \\
\hline
\end{tabular}

\footnotetext{
* Total samples screened: 644 .
} 
Table 2. Screening patterns of HCV among the MIC-exposed cohort*

\begin{tabular}{llcccc}
\hline \multirow{2}{*}{$\begin{array}{c}\text { Age } \\
\text { (years) }\end{array}$} & Sex & \multicolumn{2}{c}{ ELISA (anti-HCV) } & \multicolumn{2}{c}{ Real Time PCR } \\
\cline { 3 - 6 } & & positive & negative & positive & negative \\
\hline $28-40$ & male & 3 & 41 & 3 & 41 \\
& female & 6 & 15 & 6 & 15 \\
$40-60$ & male & 28 & 68 & 31 & 65 \\
& female & 25 & 42 & 25 & 42 \\
$60-80$ & male & 17 & 22 & 17 & 22 \\
& female & 7 & 10 & 7 & 10 \\
\hline
\end{tabular}

* Total samples screened: 284.

Table 3. Screening patterns of Pulmonary MTB among the MIC-exposed cohort*

\begin{tabular}{|c|c|c|c|c|c|c|c|}
\hline \multirow{3}{*}{$\begin{array}{c}\text { Age } \\
\text { (years) }\end{array}$} & \multirow{3}{*}{ Sex } & \multicolumn{4}{|c|}{ Routine bacteriological examination } & \multirow{2}{*}{\multicolumn{2}{|c|}{ Real Time PCR }} \\
\hline & & \multicolumn{2}{|c|}{ acid fast staining } & \multicolumn{2}{|c|}{ bacterial cultures } & & \\
\hline & & positive & negative & positive & negative & positive & negative \\
\hline \multirow[t]{2}{*}{$28-40$} & male & 20 & 38 & 20 & 38 & 22 & 36 \\
\hline & female & 5 & 26 & 5 & 26 & 9 & 22 \\
\hline \multirow[t]{2}{*}{$40-60$} & male & 28 & 58 & 24 & 58 & 25 & 57 \\
\hline & female & 8 & 25 & 8 & 25 & 9 & 24 \\
\hline \multirow[t]{2}{*}{$60-80$} & male & 33 & 24 & 33 & 24 & 33 & 24 \\
\hline & female & 8 & 7 & 8 & 7 & 8 & 7 \\
\hline
\end{tabular}

* Total samples screened: 280.

anti-HCV ELISA, which were later found to be positive for the presence of HCV RNA through real time PCR. Specified negative, positive and internal controls were run with each PCR test to ascertain the specificity of the assay (Table 2). In addition, genotypic analysis revealed that the maximum HCV positive subjects were infected from genotype 3 with traces of genotype 1 . The distribution of genotype 3 was observed in $85.39 \%$ cases (76 out of 89 ), while $14.44 \%$ (13 out of 89 ) patients were found to be infected with genotype1.

Surveillance of MTB infections was done for both pulmonary and extra-pulmonary occurrence. For pulmonary infections, a total of 280 subjects were screened out of which the presence of MTB DNA was confirmed in 106 samples. The maximum occurrence of these infections was observed in the males from the age group of 60-80 years. Moreover, classical detection methodologies (culture and AFB staining) failed to detect the MTB presence in 8 cases, which were later reported positive for the presence of MTB DNA (Table 3). Out of 377 extra-pulmonary cases, a total of 128 subjects were observed to be positive, while 249 subjects were reported negative. Extra-pulmonary MTB infections were more prevalent in the group of males aged 40-60. Apart from this, routine culture and AFB staining failed to detect the presence of MTB (false negative) in 27 real time PCR positive extra-pulmonary subjects. The specificity of the assay was confirmed by specified negative, 
Table 4. Screening patterns of extra-pulmonary MTB among the MIC-exposed cohort*

\begin{tabular}{|c|c|c|c|c|c|c|c|}
\hline \multirow{3}{*}{$\begin{array}{c}\text { Age } \\
\text { (years) }\end{array}$} & \multirow{3}{*}{ Sex } & \multicolumn{4}{|c|}{ Routine bacteriological examination } & \multirow{2}{*}{\multicolumn{2}{|c|}{ Real Time PCR }} \\
\hline & & \multicolumn{2}{|c|}{ acid fast staining } & \multicolumn{2}{|c|}{ bacterial cultures } & & \\
\hline & & positive & negative & positive & negative & positive & negative \\
\hline \multirow[t]{2}{*}{$28-40$} & male & 18 & 63 & 18 & 63 & 27 & 54 \\
\hline & female & 15 & 38 & 15 & 38 & 20 & 33 \\
\hline \multirow[t]{2}{*}{$40-60$} & male & 38 & 89 & 38 & 89 & 43 & 84 \\
\hline & female & 19 & 37 & 19 & 37 & 22 & 34 \\
\hline \multirow[t]{2}{*}{$60-80$} & male & 7 & 41 & 7 & 41 & 12 & 36 \\
\hline & female & 4 & 8 & 4 & 8 & 4 & 8 \\
\hline
\end{tabular}

* Total samples screened: 377.

positive and internal controls and all the real time PCR positive subjects responded positively to the standard ATT - $(\text { HERZ })_{2}(\text { HR })_{10}$ therapy (Table 4$)$.

\section{DISCUSSION}

Environmental toxin exposure often involves direct effects on health outcomes, but infectious disease transmission is typically more complex, depending on factors such as dynamic environmental and ecologic systems, patterns of contact among populations, and host immune status. However, interactions between pathogens and toxicants are undeniable and multiple points have been identified between initial environmental toxin exposure and infectious diseases like hepatitis at which toxicant pathogen interaction occurs [23]. Growing evidence also suggests that environmental toxic exposure modulates the immune system function making an individual more susceptible to MTB infections [24,25]. In addition, causal relationship between toxico-genomic/epigenetic alterations in the germ line and transgenerational propensity to develop such infections seems to be biologically plausible [26].

Isocyanates, a group of low molecular weight aromatic and aliphatic compounds containing isocyanate (-NCO-), are widely used in pesticide industry and for manufacturing polyurethane products. Detailed mechanistic insights of patho-physiological implications resulting from occupational and large-scale accidental exposures have received little attention. In-depth molecular studies have shown that exposure to MIC in-utero in the first trimester of pregnancy results in repercussion of the immune system function [26], while exposures at other ages result in significant immune-toxicity and elevated levels of circulating inflammatory biomarkers, including interleukin and cytokines [27]. Hence, the effect of such exposures on the initiation or exacerbation of various opportunistic infections as a result of immune compromised conditions is most likely. The results of the molecular surveillance patterns suggest that HBV infections are most common among the MIC-exposed cohort, followed by extra-pulmonary and pulmonary MTB and HCV infections (Table 1-4). We also observed that genotype 3 is the most prevalent $\mathrm{HCV}$ genotype among the survivors. In addition, an interesting observation was that routine qualitative investigations (HBsAg; anti-HBc, anti-HCV ELISA for HBV, HCV; culture, AFB stain for MTB) failed to diagnose the infections several times, indicating the higher prevalence of occult hepatitis and latent tuberculosis in the affected population. Therefore, there is an urgent need to institutionalize population-based large cohort studies to understand the 
genome-wide association of occult hepatitis and latent tuberculosis in the MIC-affected inhabitants of Bhopal.

The role of environmental, occupational and accidental chemical exposures in the etiology and progression of infectious diseases is beginning to be characterized. However, several important aspects need to be addressed, including individual's genotypic susceptibility to various infectious diseases to environmental exposures. Fostering collaborations between researchers and clinics can lead to a better understanding of complex exposures and infectious diseases related to them. The pace of immune function changes resulting from gene-environmental interaction at the population level needs to be characterized for translational utility.

\section{ACKNOWLEDGEMENT}

The authors gratefully acknowledge Bhopal Memorial Hospital Trust for providing necessary financial support.

\section{REFERENCES}

1. Crinnion WJ. Environmental medicine, part one: the human burden of environmental toxins and their common health effects. Altern Med Rev 2000;5:52-63.

2. Inadera H. The immune system as a target for environmental chemicals: Xenoestrogens and other compounds. Toxicol Lett 2006;164:191-206.

3. Faust F, Kassie F, Knasmüller S, Kevekordes S, Mersch-Sundermann V. Use of primary blood cells for the assessment of exposure to occupational enotoxicants in human biomonitoring studies. Toxicology 2004;198:341-50.

4. Battershill JM, Burnett K, Bull S. Factors affecting the incidence of genotoxicity biomarkers in peripheral blood lymphocytes: impact on design of biomonitoring studies. Mutagenesis 2008;23:423-37.

5. Coronas MV, Pereira TS, Rocha JA, Lemos AT, Fachel JM, Salvadori DM, et al. Genetic biomonitoring of an urban population exposed to mutagenic airborne pollutants. Environ Int 2009;35:1023-9.
6. Mishra PK, Samartha RS, Pathak N, Jain SK, Banerjee S, Maudar KK. Bhopal gas tragedy: review of clinical and experimental findings after 25 years. Int J Occup Med Environ Health 2009;22:193-202. DOI 10.2478/v10001-009-0028-1.

7. Crabb C. Revisiting the Bhopal tragedy. Science 2004;306: $1670-1$.

8. Mishra PK, Gorantla VR, Akhtar N, Tamrakar P, Jain SK, Maudar KK. Analysis of cellular response to isocyanate using $N$-succinimidyl $N$-methylcarbamate exposure in cultured mammalian cells. Environ Mol Mutagen 2009;50:328-36.

9. Mishra PK, Raghuram GV, Panwar H, Jain D, Pandey H, Maudar KK. Mitochondrial oxidative stress elicits chromosomal instability after exposure to isocyanates in human kidney epithelial cells. Free Radic Res 2009;43:718-28.

10. Mishra PK, Bhargava A, Raghuram GV, Jatawa SK, Akhtar N, Khan S, et al. Induction of genomic instability in cultured human colon epithelial cells following exposure to isocyanates. Cell Biol Int 2009;33:675-83.

11. Mishra PK, Bhargava A, Raghuram GV, Gupta S, Tiwari S, Upadhyaya R, et al. Inflammatory response to isocyanates and onset of genomic instability in cultured human lung fibroblasts. Genet Mol Res 2009;8:129-43.

12. Raghuram GV, Pathak N, Jain D, Panwar H, Pandey H, Mishra PK, et al. Molecular mechanisms of isocyanate induced oncogenic transformation in ovarian epithelial cells. Rep Toxicol 2010;30:377-86.

13. Sriramachari S, Chandra H. The lessons of Bhopal [toxic] MIC gas disaster scope for expanding global biomonitoring and environmental specimen banking. Chemosphere 1997;34:2237-50.

14. Mishra PK, Jatawa SK, Raghuram GV, Pathak N, Jain A, Tiwari A, et al. Correlation of aberrant expression of $p 53$, Rad50, and cyclin-E proteins with microsatellite instability in gallbladder adenocarcinomas. Genet Mol Res 2009;8:1202-10.

15. Mishra PK, Panwar H, Bhargava A, Gorantla VR, Jain SK, Banerjee $\mathrm{S}$, et al. Isocyanates induces DNA damage, apoptosis, oxidative stress, and inflammation in cultured human lymphocytes. J Biochem Mol Toxicol 2008;22:429-40. 
16. Mishra PK, Khan S, Bhargava A, Panwar H, Banerjee S, Jain SK, et al. Regulation of isocyanate-induced apoptosis, oxidative stress, and inflammation in cultured human neutrophils: Isocyanate-induced neutrophils apoptosis. Cell Biol Toxicol 2010;26:279-91.

17. Balmes J, Rempel D, Alexander M, Reiter R, Harrison R, Bernard B, et al. Hospital records as a data source for occupational disease surveillance: a feasibility study. Am J Ind Med 1992;21:341-51.

18. Mishra PK, Bhargava A, Punde RP, Pathak N, Desikan P, Jain A, et al. Diagnosis of gastrointestinal tuberculosis: combining cytomorphology, microbiology, immunology \& molecular techniques - a study from Central India. Ind J Clin Biochem 2010;25:68-73.

19. Mishra PK, Gorantla VR, Bhargava A, Varshney S, Vashistha P, Maudar KK. Molecular detection of Mycobacterium tuberculosis in formalin-fixed, paraffin-embedded tissues and biopsies of gastrointestinal specimens using real-time polymerase chain reaction system. Turk J Gastroenterol 2010;21:129-34.

20. Khan S, Bhargava A, Pathak N, Maudar KK, Varshney S, Mishra PK. Circulating biomarkers and their possible role in pathogenesis of chronic hepatitis $B$ and $C$ viral infections. Ind J Clin Biochem. In press 2011. DOI 10.1007/s12291-010-0098-7.

21. Bhargava A, Khan S, Panwar H, Pathak N, Punde RP, Varshney $\mathrm{S}$, et al. Occult hepatitis $B$ virus infection with low viremia induces DNA damage, apoptosis and oxidative stress in peripheral blood lymphocytes. Virus Res 2010;153:143-50.

22. Mishra PK, Bhargava A, Khan S, Pathak N, Punde RP, Varshney S. Prevalence of hepatitis $C$ virus genotypes and impact of Thelper cytokines in achieving sustained virological response during combination therapy: a study from Central India. Indian J Med Microbiol 2010;28:358-62.

23. Black H. Bringing the Bugs Back In: Environmental Health Research Model Combines Toxicology and Infectious Disease. Environ Health Perspect 2010;118:a353.

24. Rieder HL. Socialization patterns are key to the transmission dynamics of tuberculosis. Int J Tuberc Lung Dis 1999;3:177-8.

25. Pokhrel AK, Bates MN, Verma SC, Joshi HS, Sreeramareddy CT, Smith KR. Tuberculosis and indoor biomass and kerosene use in Nepal: a case-control study. Environ Health Perspect 2010;118:558-64.

26. Mishra PK, Dabadghao S, Modi G, Desikan P, Jain A, Mittra I, et al. In-utero exposure to methyl isocyanate in the Bhopal gas disaster: evidence of persisting hyper-activation of immune system two decades later. Occup Environ Med 2009;66:279.

27. Bhargava A, Punde RP, Pathak N, Dabadghao S, Desikan P, Mishra PK, et al. Status of inflammatory biomarkers in the population that survived the Bhopal gas tragedy: a study after two decades. Ind Health 2010;48:204-8.

This work is available in Open Access model and licensed under a Creative Commons Attribution-NonCommercial 3.0 Poland License - http://creativecommons.org/ licenses/by-nc/3.0/pl/deed.en. 